\title{
Lentiviral-mediated multiple gene transfer to chondrocytes promotes chondrocyte differentiation and bone formation in rabbit bone marrow-derived mesenchymal stem cells
}

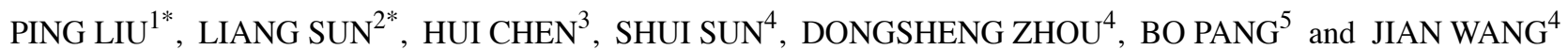 \\ ${ }^{1}$ Department of Pharmacy and ${ }^{2}$ Department of Urology, Shandong Provincial Hospital Affiliated to Shandong \\ University, Jinan, Shandong 250021; ${ }^{3}$ Department of Orthopaedics, Chinese People's Liberation Army General Hospital, \\ Beijing 100853; ${ }^{4}$ Department of Orthopaedics, Shandong Provincial Hospital Affiliated to Shandong University; \\ ${ }^{5}$ Department of Neurosurgery, Qilu Hospital, Shandong University, Jinan, Shandong 250012, P.R. China
}

Received May 26, 2015; Accepted July 2, 2015

DOI: $10.3892 / o r .2015 .4241$

\begin{abstract}
The aim of the present study was to provide a theoretical and experimental foundation on the differentiation of stem cells through the induction of multiple genes. The lentiviral vector carrying $T G F-\beta 1$ and $I L-10$ genes was transfected to bone marrow-derived mesenchymal stem cells (BMSCs) which differentiated into chondrogenesis. Healthy New Zealand white rabbits, 2-3 months of age were used in the present study. A 6-8 $\mathrm{ml}$ of bone marrow was isolated from the iliac and tibial shaft of each rabbit. The BMSCs suspension was aspired following centrifugation of the bone marrow by percoll separating medium. The BMSCs were primarily cultured and subcultured in vitro, then divided into four groups according to the difference of lentivirus vectors: group A, receiving transforming growth factor $\beta 1$ (TGF- $\beta 1$ ); group B, receiving TGF- $\beta 1$ and Interleukin-10 (IL-10); group C, empty vector transfection; and group D, receiving no cell growth factor. Fluorescence expression was detected $12 \mathrm{~h}$ after transfecting the lentiviral vector carrying the $T G F-\beta 1$ and $I L-10$ gene to BMSCs. The transfection efficiency was approximately $70 \%$ with a MOI=100 after $96 \mathrm{~h}$. Expression of SOX-9 aggrecan and Type II collagen in groups A-E on day 7 and 14 was detected by RT-PCR and western blot analysis. The expression level of three genes expressed in groups $\mathrm{A}$ and $\mathrm{C}$ were higher compared to the expression in groups B, D and E. The expression level of
\end{abstract}

Correspondence to: Professor Jian Wang, Department of Orthopaedics, Shandong Provincial Hospital Affiliated to Shandong University, 324 Jingwu Road, Jinan City, Shandong 250012, P.R. China

E-mail: 330632664@qq.com

*Contributed equally

Key words: lentivirus, gene transfection, bone marrow-derived mesenchymal stem cells, chondrocytes, transforming growth factor $\beta 1$, interleukin-10, interleukin- $1 \beta$, cartilage defect the three genes expressed in group B was higher compared to the expression in group D. The expression level of three genes expressed in group A and $\mathrm{C}$ showed no statistical difference. Cytokines therefore play an important role in cell proliferation and chondrogenic differentiation. TGF- $\beta 1$ has a synergistic effect in the differentiation. In addition, IL-10 may have a protective role in the restoration of cartilaginous tissue.

\section{Introduction}

Damage to articular cartilage is the source of considerable disability in the form of arthritis and trauma (1). Adult articular chondrocytes lack an effective intrinsic capacity for self-repair. Loss of articular cartilage substance results in damage that is generally permanent and often progressive (2). A number of studies have shown that TGF- $\beta 1$ can induce mesenchymal stem cells (MSCs) to differentiate into cartilage cells, promote the proliferation and maturation of the cartilage cells, and enhance the synthesis of the cartilage cells and the secretion of proteoglycan and type II collagen. It is optimal to induce the differentiation of stem cells into cartilage cells (3). Cytokine IL-10 was identified in 1989 by Fiorentino et al (4) as an immune mediator that is secreted by mouse type 2 T-helper cell clones (Th2) and inhibits the synthesis of IL-2 and interferon (IFN) in Th1 cell clones. Since it was initially identified, IL-10 has been extensively investigated. The key function appears to be the inhibition of innate and acquired immune responses by means of suppression of monocyte/macrophage activity as well as inhibition of the development of effector T-cells. In addition to these effects, IL-10 regulates the function and/or differentiation of B cells, NK cells, mast cells, granulocytes, dendritic cells and some connective tissue cell types (5). Accumulating evidence has identified the role of IL-10 in regulating connective tissues homeostasis and extracellular matrix (6-8). Cartilage, a typical connective tissue that mainly consists of an abundant collagen type II-rich and proteoglycan-rich extracellular matrix, is synthesized by chondrocytes. Only $3-5 \%$ of the cartilage volume is represented by chondrocytes, the single cell type in cartilage that is responsible for maintaining extracellular 
matrix integrity. Chondrocytes are protected from the immune system, because they are separated from exogene stimuli by their encapsulation with a dense impenetrable extracellular cartilage matrix. However, chondrocytes are highly activated by cytokines. Although previous findings have identified a protective role of IL-10 in the inflamed joint, the particular impact of IL-10 on cartilage and chondrocyte biology is poorly understood. Under inflammatory conditions, IL-10 may exhibit immunoregulatory effects on the activated chondrocytes in articular cartilage.

Regional gene therapy has the potential to be developed as one aspect of a comprehensive tissue engineering strategy to manage a variety of bone repair scenarios (15-17). The advantages of regional gene therapy are the duration of protein production that can be determined by the vector selected and theoretically multiple transgenes that may be delivered to a specific anatomic site (15-19). Lentivirus is a common transgenic carrier used in laboratories due to its high infection efficiency and stable expression of transfected genes (20-22). It was previously reported that the treatment effect of the Lv-BMP-mediated hBMP2 gene that was overexpressed in osteoporotic rBMSCs formed by in vitro genetic infection on local osteoporosis was more beneficial than that performed by in vivo genetic infection (9). Focus has been directed towards the development of alternative vectors, such as lentivirus, which is based on the human immunodeficiency virus (11). Lentivirus is known to transduce dividing and non-dividing cells and incorporate them into the host genome (ref?). Furthermore, lentiviral vectors have demonstrated high levels of stable gene transfer and target gene expression (10). Additionally, minimal immunogenicity is associated with the lentiviral vectors (11), a significant advantage over gene therapy systems involving adenovirus. However, similar to adenoviral vectors, the safety profile of lentivirus needs to be addressed before these vectors are to be used to treat patients with non-lethal conditions (12).

In the present study, we investigated the role of TGF- $\beta 1$, IL-10 and IL-1 $\beta$ in chondrocyte differentiation using New Zealand white rabbits and lentiviral vectors carrying multiple genes transfected to BMSCs.

\section{Materials and methods}

Isolation, culturing and induction of rBMSCs. Bone marrow was harvested from New Zealand white rabbits aged 2-3 months and weighing 1.8-2.4 kg under sterile conditions as described in a previous study (?). The two ends of the femora were separated at the epiphysis and the marrow was washed using low glucose Dulbecco's modified Eagle's medium ( $\alpha$-MEM; Gibco BRL, Grand Island, NY, USA) supplemented with $10 \%$ (v/v) fetal bovine serum (FBS; Hyclone, Logan, UT, USA). To obtain a single-cell suspension, the marrow was gently kneaded in L-DMEM containing 10\% FBS. Cell activity prior to cell culturing was analyzed using trypan blue (Guangzhou Genebase Bioscience Co., Ltd., Guangzhou, China) staining. The percentage of cell activity was calculated as per the formula: cell activity $(\%)=[($ total cells - stained cells $) /$ total cells] x $100 \%$. The percentage of cell activity was $>96 \%$ in all the groups. Experimental procedures were carried out at a facility accredited by the Institutional Animal Care and Use Committee of Shandong University. The culture medium was initially changed on the 4-5th day after which non-adherent cells were discarded. After $90 \%$ confluence was reached, the BMSCs were excreted from the culture substratum using trypsin/EDTA (0.25\% w/v trypsin, 0.02\% EDTA) (Hyclone) and were transfered to the culture dishes $(10 \mathrm{~cm}$ in diameter) at $1.0 \times 10^{5} \mathrm{cell} / \mathrm{s} / \mathrm{ml}$ in $10 \mathrm{ml}$. The characterization of rabbit BMSCs was confirmed using a flow cytometry assay, as described in a previous study (?).

Transduction of rBMSCs with lentivirus-delivered IL-10. The full-length coding sequence of IL-10 [1306 base pairs (bp), accession no: NM_010548·2] was cloned into a lentivirus-based plasmid construct (pHR'CS-IL-10). A vesicular stomatitis virus glycoprotein pseudotyped lentiviral vector was generated by transient transfection of three plasmids into human embryonic kidney 293T cells with Lipofectamine 2000 transfection reagent (Invitrogen Life Technologies, Carlsbad, CA, USA). The viral vector was examined by Southern blot analysis on genomic DNA isolated from infected U2OS cells.

After the multiplicity of infection (MOI) and the infection efficiency were determined, the lentivirus hosting the PHR'CS-IL-10 was introduced into MSCs at a MOI of $10 \mathrm{in}$ $\alpha$-MEM for $24 \mathrm{~h}$ with $10 \mu \mathrm{g} / \mathrm{ml}$ polybrene (Sigma-Aldrich, St. Louis, MO, USA). Infected MSCs were washed twice after $12 \mathrm{~h}$, and bright green fluorescence was observed under an inverted fluorescence microscope (Leica, Mannheim, Germany). The culture supernatant containing secreted IL-10 was examined for 7 days. IL-10 expression was validated further by an enzyme-linked immunosorbent assay (ELISA).

ELISA for TGF- $\beta 1$ and IL-10. TGF- $\beta 1$ and IL-10 were quantified using an ELISA kit (Quantikine, R\&D Systems, Minneapolis, MN, USA) according to the manufacturer's instructions. The cells were lysed to determine the total protein content for the standardization of TGF- $\beta 1 / \mathrm{IL}-10$ and the total protein content was determined using a DC protein assay kit (Bio-Rad Laboratories, Hercules, CA, USA) using bovine serum albumin as a standard. The adherent RBMCs were rinsed twice with $1 \%$ PBS and then lysed using a cell culture lysis reagent while still adherent to the culture dish. The lysed cell debris was transferred to a microcentrifuge tube and the content was microcentrifuged for $30 \mathrm{sec}$. The supernatant was incubated with $100 \mathrm{ml}$ D-luciferin and luciferase activity was quantified on a luminometer. Each sample was repeated in triplicate and the results were reported as luciferase activity/total protein/24 $\mathrm{h}$.

Toluidine blue staining for cartilage cell identification. The cartilage cells were induced 14 days after transfection. A solution consisting of $70 \%$ ethanol and $0.2 \%$ toluidine blue was used to stain the cartilage cells overnight. Subsequently, gradient alcohol dehydration was performed, dimethylbenzene was transparent and neutral gum was used for sealing. The cells were fixed in $4 \%$ paraformaldehyde for $15 \mathrm{~min}$ and observed for the secretion of glycosaminoglycan using an inverted microscope.

RT-PCR detection of the expression of genes associated with the differentiation into cartilage cells. The expression of genes associated with the differentiation in cartilage 
Table I. PCR primer sequences and product lengths.

\begin{tabular}{llll}
\hline Gene & \multicolumn{1}{c}{ Forward primer } & Reverse primer & Length (bp) \\
\hline Aggrecan & CCTACCAGGACAAGGTCTCG & CCGATAGTGGAACACAACACC & 179 \\
SOX-9 & CTGGAGACTGCTGAACGAGAG & CCATTCTTCACCGACTTCCTC & 129 \\
Type II collagen & GCCTGTGTCTGCTTTTTCTGT & AAGATTCCAGTTGTTGGGTCA & 120 \\
GAPDH & ATGGGGAAGGTGAAGGTCG & TAAAAGCAGCCCTGGTGACC & 119 \\
\hline
\end{tabular}

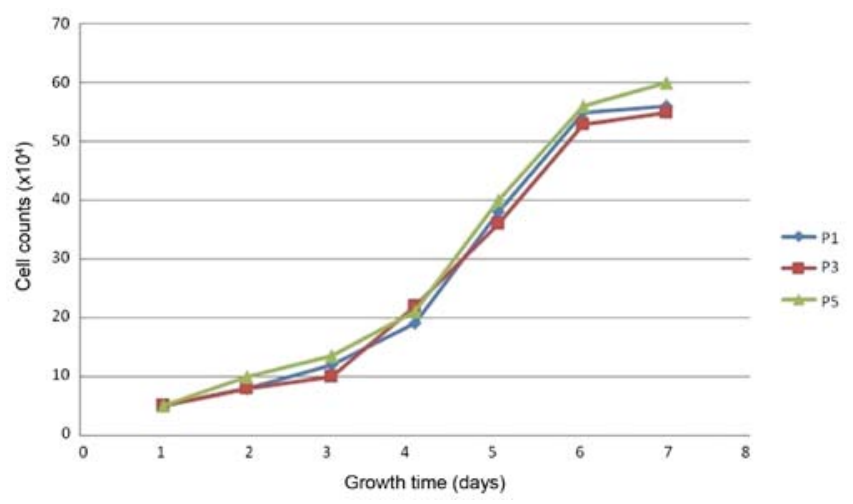

Figure 1. Growth curve of BMSCs of P1, P3 and P5 generation.

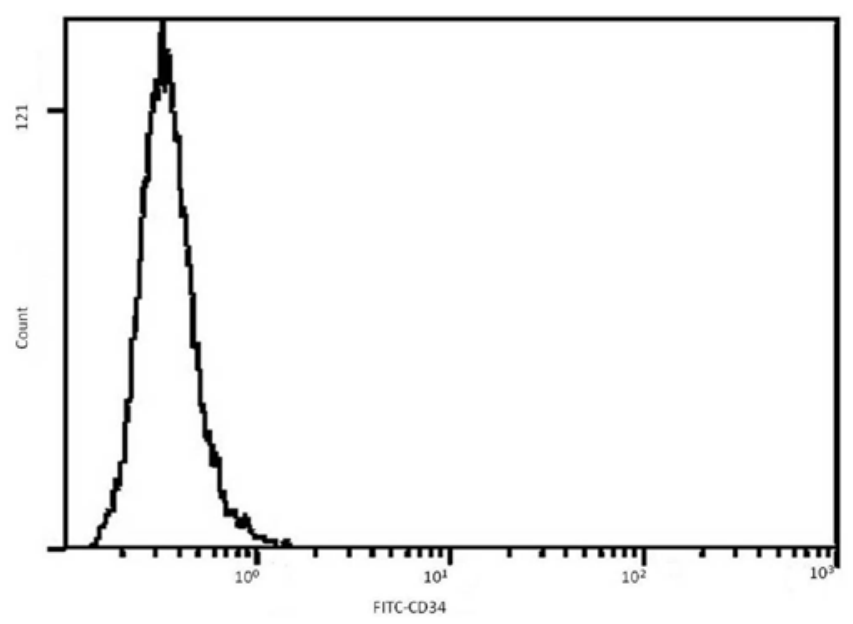

Figure 2. Flow cytometry of FITC-CD34 in the P3 generation.

cells was determined by RT-PCR analysis using standard methods. Total RNA was extracted from cell pellets using the TRIzol reagent and amplified by reverse transcription-PCR (RT-PCR) according to the manufacturer's instructions, respectively. A housekeeping gene, glyceraldehyde 3-phosphate dehydrogenase $(G A P D H)$, was used as an endogenous control. GAPDH and related genes primers were constructed by using Primer 5 Software and verified by DNA sequencing analysis. GAPDH (1382 bp) primers are provided in Table I.

Western blot detection of type II collagen secreted by cartilage cells. The cells were washed with PBS three times and digested by $0.25 \%$ trypsin for 2 min on days 7,14 and 21 . The digestion was terminated by the addition of culture medium containing 10\% FBS. After blowing for $3 \mathrm{~min}$, the cell suspension was transferred to a centrifugal tube for centrifugation at 1,500 rpm for $3 \mathrm{~min}$. The supernatant was discarded and Trizol was added to extract the total protein of the digestive cells. GAPDH was used as positive reference. The 10\% SDS-PAGE (Bio-Rad vertical electrophoresis system) was conducted under the conditions of $10 \mu \mathrm{l}$ sample, $110 \mathrm{~V}$ and $60 \mathrm{~min}$. Then $15 \mathrm{~V}$ was applied for trans-blotting for 70 min (Bio-Rad Trans-blot SD semi-dry transfer). Anti-rabbit type II collagen polyclonal antibody (Calbiochem, San Diego, CA, USA) of $5 \mu$ was diluted with $5 \mathrm{ml} 10 \%$ TBST 1:1,000. The cells were incubated at $4^{\circ} \mathrm{C}$ overnight. After being washed with 10\% TBST three times (5 min/time), 1:1,000 mouse antirabbit IgG was added. After $1 \mathrm{~h}$ of incubation, the cells were washed by $10 \%$ TBST three times ( $5 \mathrm{~min} / \mathrm{time}$ ). ECL staining and scanning were conducted for quantitative analysis.

Statistical analysis. Quantitative results were presented as mean \pm standard deviation (SD). Experiments were performed in triplicate. Independent sample t-test and one way analysis of variance (ANOVA) followed by Student Newman Keuls (SNK) post hoc analysis were performed with SPSS, v.13.0. Values were considered statistically significant at $\mathrm{P}<0.05$.

\section{Results}

Growth curve of rabbit BMSCs. BMSCs of P1, P3 and P5 generation were counted and a growth curve was drawn. The results showed that the first 2 days were the slow growth period, while 3-6 days were the rapid growth period and on the 7th day it entered the platform period (Fig. 1).

Detection of cell surface markers on rabbit BMSCs. Flow cytometry was used to detect cell surface markers on BMSCs of P3. The positive rate of CD34 was 2.0\% (Fig. 2) and of CD44 was $97.6 \%$ (Fig. 3).

Determination of the viral titer of 2937 cells. 293T cells were planked and $\sim 60-70 \%$ of the cells were fused on the following day. Subsequently, the virus buffer was added and the cells were observed under the microscope after $24 \mathrm{~h}$. Only viable cells were observed in each well using visible light. Fluorescence expression was detected after $96 \mathrm{~h}$ of growth (Fig. 4). Fluorescence microscopy showed that the number of fluorescent cells decreased with the corresponding increase of the dilution ratio of the virus buffer. The viral titers of the viral stock solution (TGF- $\beta 1$ and IL-10) in the last 


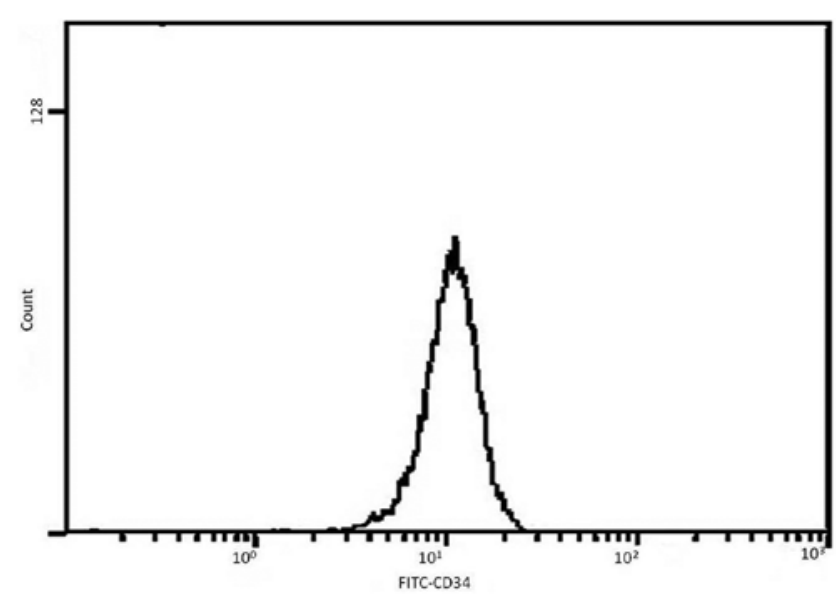

Figure 3. Flow cytometry of FITC-CD44 in the P3 generation.

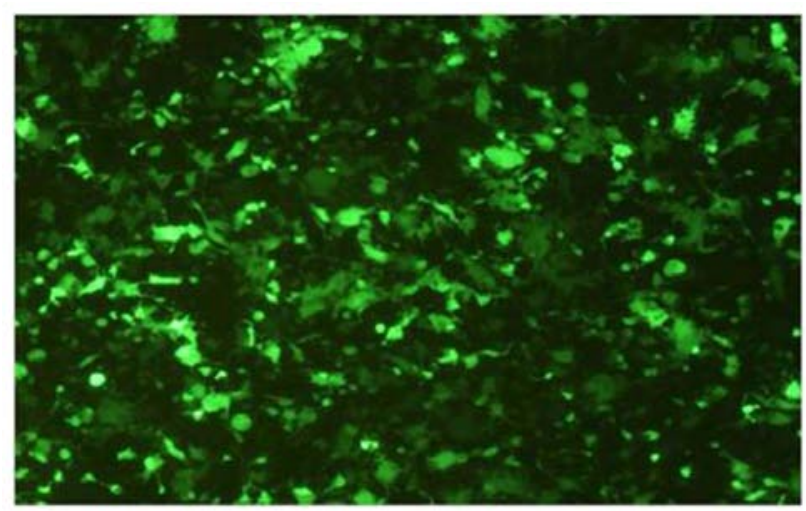

Figure 4. Determination of the viral titer of 293T cells.

two wells of the 96-well plate were obtained by counting the number of fluorescent cells in the last two wells divided by the corresponding dilution ratios.

MOI of rabbit BMSCs. The virus group with a MOI=1, 10, 100 and the polybrene group with a $\mathrm{MOI}=1,10,100$ were observed under the microscope after $24 \mathrm{~h}$. A small amount of dead cells was resuspended (Figs. 5 and 6) and there was no obvious change of BMSCs cell morphology. In the above two groups with a $\mathrm{MOI}=200$, more resuspended dead cells were observed. BMSCs were shrunk and transformed, with unclear nuclei and disappeared nucleoli. A few cells expressed fluorescence under the fluorescent microscope after $24 \mathrm{~h}$ of liquid change, especially when $\mathrm{MOI}=100$. The expression rate of GFP or RFP was increased after $96 \mathrm{~h}$. Under fluorescence microscopy, the maximum efficiency was measured in polybrene with MOI=100 and the transfected efficiency, as determined by FCM, was $70.2 \%$ which was the optimal MOI (Figs. 7 and 8).

Single-or double-gene-transfected BMSCs mediated by lentiviral vector. The cells were divided into four groups based on the lentiviral vectors: group A: TGF- $\beta 1$; group B: TGF- $\beta 1+$ IL-10; group C: blank vector; and group D: blank control group. After $24 \mathrm{~h}$, the virus was added and the groups were observed. A small amount of resuspended cells was evident in group A (TGF- $\beta 1)$, group B (TGF- $\beta 1+$

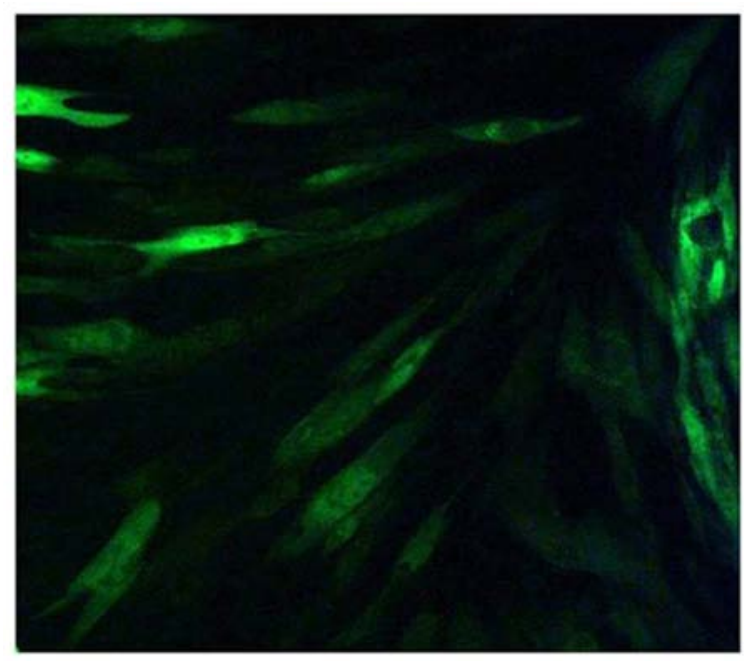

Figure 5. Fluorescence microscopy of BMSCs affected with lenti-TGF $31-G F P$ (MOI=10 after $96 \mathrm{~h}$.

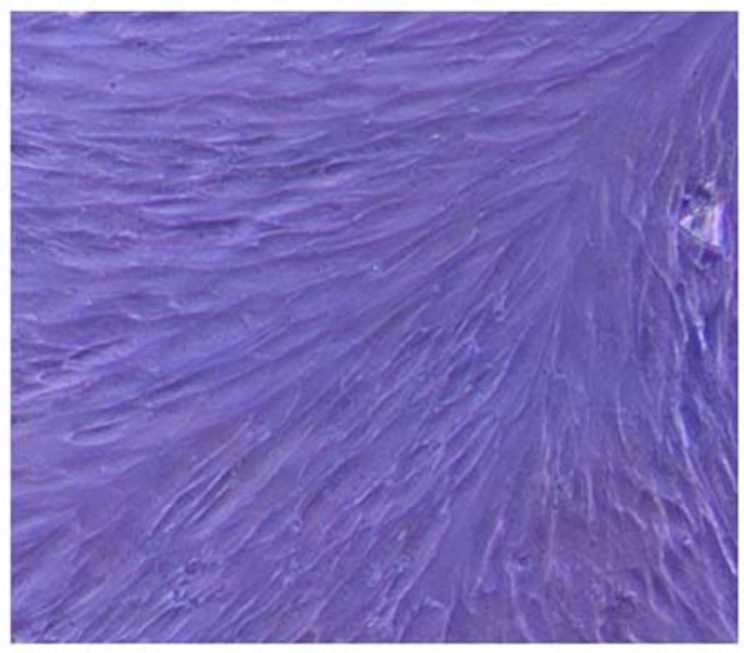

Figure 6. Cell morphology of BMSCs affected with lenti-TGF $\beta 1-G F P$ (MOI=10) after $96 \mathrm{~h}$. No obvious change of cell morphology was observed and there were almost no dead cells.

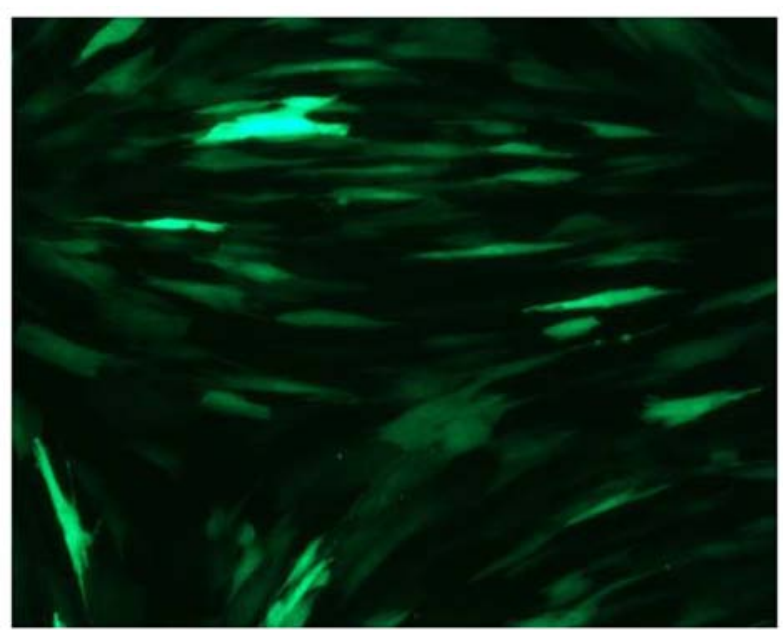

Figure 7. Fluorenscence microscopy of BMSCs affected with lenti-TGF $\beta 1$-GFP (MOI=100) after $96 \mathrm{~h}$. 


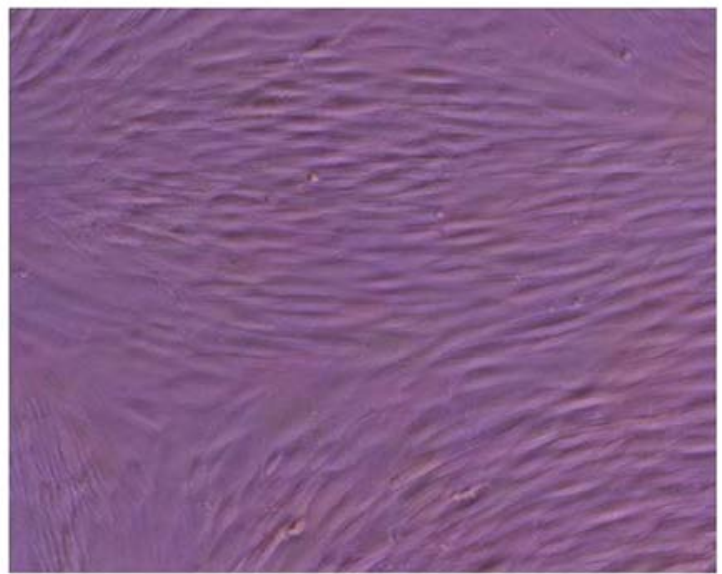

Figure 8. Cell morphology of BMSCs affected with lenti-TGF- $\beta 1-G F P$ $(\mathrm{MOI}=100)$ after $96 \mathrm{~h}$. No obvious changes were evident in cell morphology and only a few cells died.

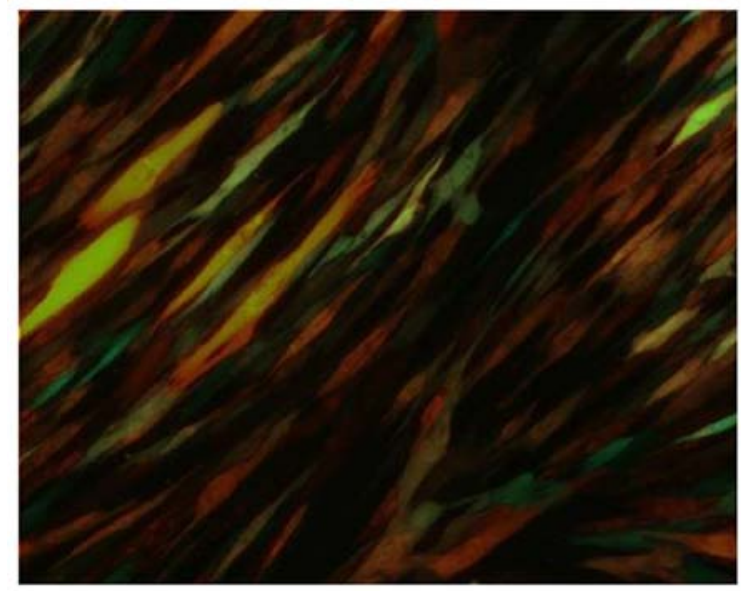

Figure 9. BMSCs treated with lenti-TGF- $\beta 1-G F P$ and lenti-IL10-RFP (MOI=100) after $96 \mathrm{~h}$.

IL-10) (Figs. 9 and 10) and group C (blank vector group), although no obvious changes were evident in cell morphology. No cells died in group D (control group). Fluorescence microscopy showed that only a few cells expressed GFP or RFP following the addition of the lentiviral vector. The expression levels of GFP or RFP were observed daily and the signals gradually increased. The infected efficiency was $\sim 70-75 \%$ after $96 \mathrm{~h}$ as determined by FCM.

Expression level of targeted TGF- $\beta 1$ and IL-10 genes in the supernatants. An ELISA method was used to detect the level of TGF- $\beta 1$ in the supernatant. The level of TGF- $\beta 1$ was $(24.78 \pm 2.75) \mathrm{pg} / \mathrm{ml}$ in group A (TGF- $\beta 1)$ and $(25.02 \pm 3.43) \mathrm{pg} / \mathrm{ml}$ in group B (TGF- $\beta 1+\mathrm{IL}-10)$. In group C (blank vector group) and group D (control group), there was no gene expression detected. Statistical analysis revealed that there were significant differences between gene-transfected groups and non-gene-transfected groups $(\mathrm{P}<0.05)$.

An ELISA method was used to detect the level IL-10 in the supernatant, which was $(32.08 \pm 2.95) \mathrm{ng} / 1$ in group B (TGF- $\beta 1+\mathrm{IL}-10)$. In group A (TGF- $\beta 1$ ), group C (blank vector

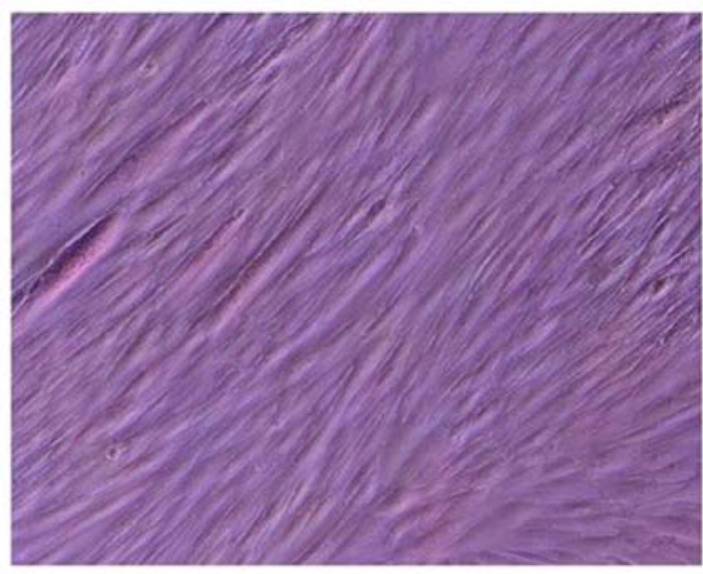

Figure 10. BMSCs treated with lenti-TGF- $\beta 1$-GFP and lenti-IL10-RFP (MOI=100) after $96 \mathrm{~h}$. No morphological changes were observed.

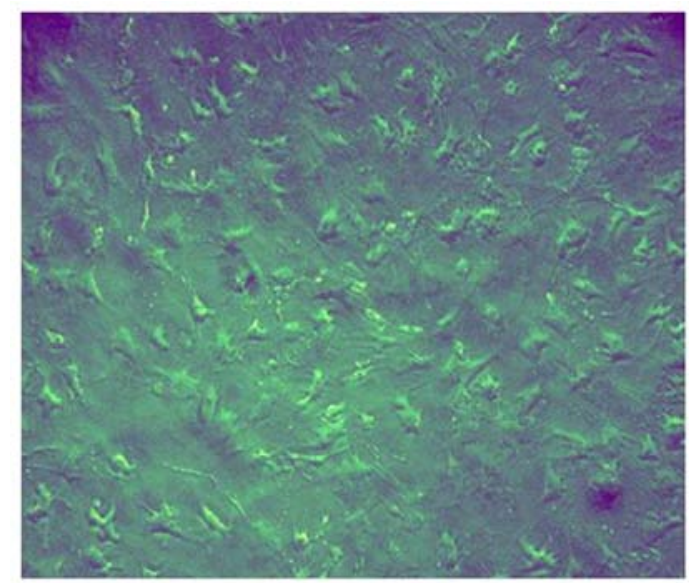

Figure 11. Phase contrast microscopy of BMSCs in group A (single-transfected group). After 3-4 days after induction of chondrogenesis a small amount of cells were shorter and the protuberance was reduced.

group) and group D (control group), there was no gene expression detected. Statistical analysis revealed that there were differences between group $\mathrm{B}$ and the all other groups $(\mathrm{P}<0.05)$.

Cell morphology. Phase contrast microscopy showed that 3-4 days after induction a small amount of cells was shorter and the protuberance was reduced. After 7 days of culturing, cell proliferation was accelerated and most cells were deformed. The protuberance was significantly decreased and some cells were round shaped (Fig. 11). After 14 days of culturing, cell proliferation was highly accelerated and the majority of the cells were round shaped. Specifically, the protuberance disappeared, which was similar to the cartilage cells (Fig. 12).

Alcian blue staining after the induction of chondrogenesis of BMSCs. The cells gradually aggregated 2-3 days after induction and differentiation of chondrogenesis. Patchy or nodular cell clusters with high density were evident in sites where cells accumulated until the 7th day. After 14 days of induction the number of aggregated cell clusters increased in number and volume. Highly aggregated cell clusters had a patchy or nodular shape. The smooth surface was colloid and the surrounding 


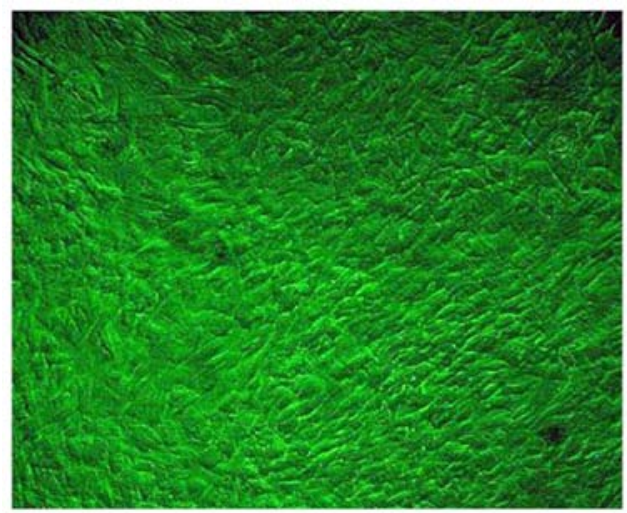

Figure 12.Phase contrast microscopy of BMSCs in group A (single-transfected group) 14 days after induction of chondrogenesis. Cell proliferation was highly accelerated and the majority of the cells were round shaped. The protuberance was disappeared, which was similar to the cartilage cells.

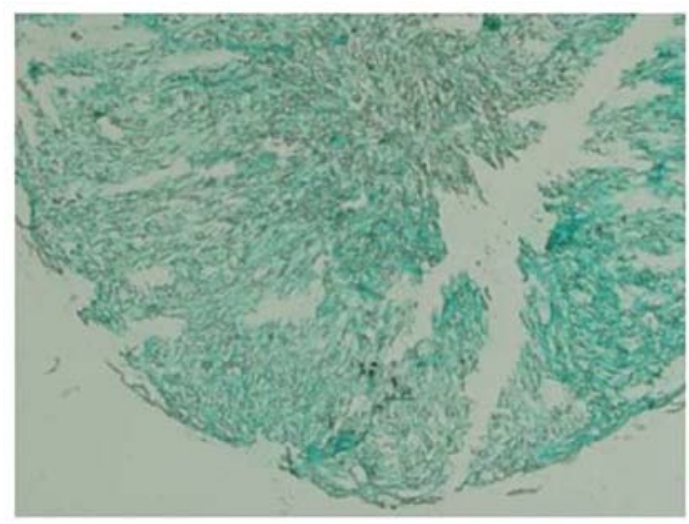

Figure 13. Alcian blue staining after induction of chondrogenesis of BMSCs in group A (single-transfected group). The nodular and surrounded aggregated cells are in pale blue.

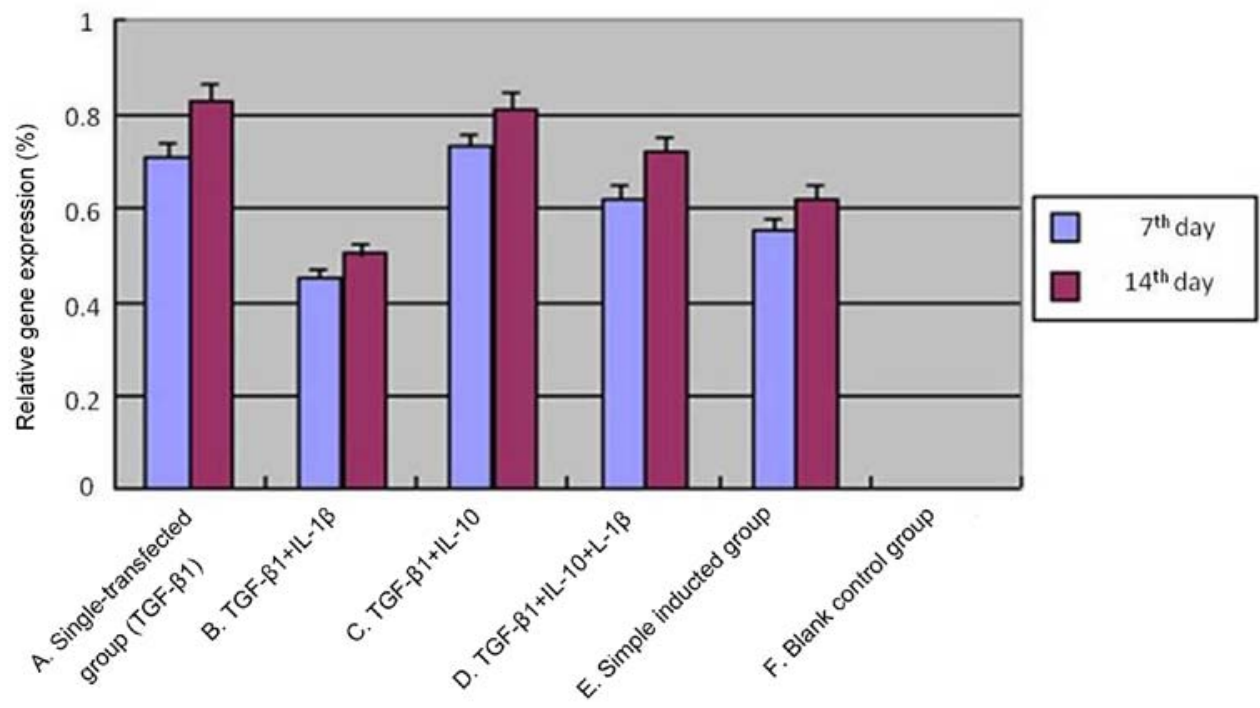

Figure 14. Relative quantification of the gene expression of SOX-9.

cells were radial. The nodular and surrounded aggregated cells were pale blue subsequent to Alcian blue staining (Fig. 13).

mRNA expression of BMSCs-induced chondroblasts. Previous results showed that the three targeted genes were all expressed in group A-E, but there was no expression in group F (blank control group) after 14 days of culturing. The expression levels of SOX-9, aggrecan and Type II collagen were significantly higher in group $\mathrm{A}$ and $\mathrm{C}$ compared to group $\mathrm{B}$ and $\mathrm{D}$ (containing IL-1 $\beta$ ) and the blank vector group, and the differences were statistically significant. In group D (TGF- $\beta 1+\mathrm{IL}-10+\mathrm{IL}-1 \beta)$, the expression levels of the target genes were higher than those of group B (TGF- $\beta 1+\mathrm{IL}-1 \beta)$, with statistical significance $(\mathrm{P}<0.05)$. No significantly statistical differences of targeted genes between group A (TGF- $\beta 1$ ) and group C (TGF- $\beta 1+\mathrm{IL}-10$ ) ( $\mathrm{P}>0.05)$ were observed (Figs. 14-16).

Protein expression of BMSCs-induced chondroblasts. Western blot analysis of Type II collagen after 21-days induction of BMSCs showed that there was no significantly statistical difference of grey levels between groups $\mathrm{A}, \mathrm{C}$ and $\mathrm{E}$ $(\mathrm{P}>0.05)$. Grey levels of group D (TGF- $\beta 1+\mathrm{IL}-10+\mathrm{IL}-1 \beta)$ were higher than that of group B (TGF- $\beta 1+$ IL-1 $\beta)$ and there was a statistical significance $(\mathrm{P}<0.05)$ (Fig. 17).

\section{Discussion}

Several cytokines, hormones and growth factors are known to influence the anabolic and catabolic processes of chondrocytes. Therefore, a number of growth factors, including transforming growth factor (TGF- $\beta$ ), insulin-like growth factor (IGF-1), bone morphogenetic proteins (BMPs) and to a lesser extent fibroblast growth factors (FGFs) and epidermal growth factor (EGF), have been used in cartilage tissue engineering studies in vitro to promote the chondrogenic phenotype and to stimulate ECM production and to promote chondrogenesis of MSCs. Several members of the TGF- $\beta$ superfamily play a major role in cartilage development and repair. Mainly, the isoforms TGF- $\beta 1,2$ and 3 enhance chondrocyte proliferation and increase ECM synthesis by 


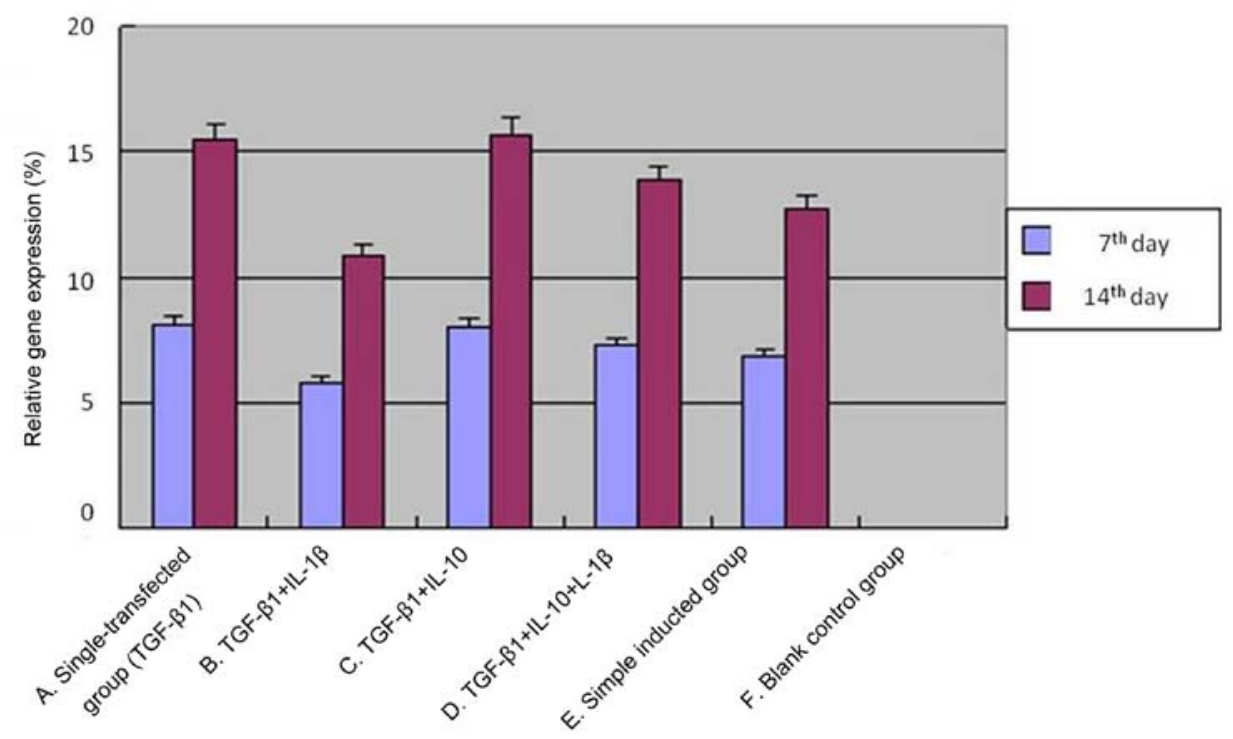

Figure 15. Relative quantification of the gene expression of aggrecan.

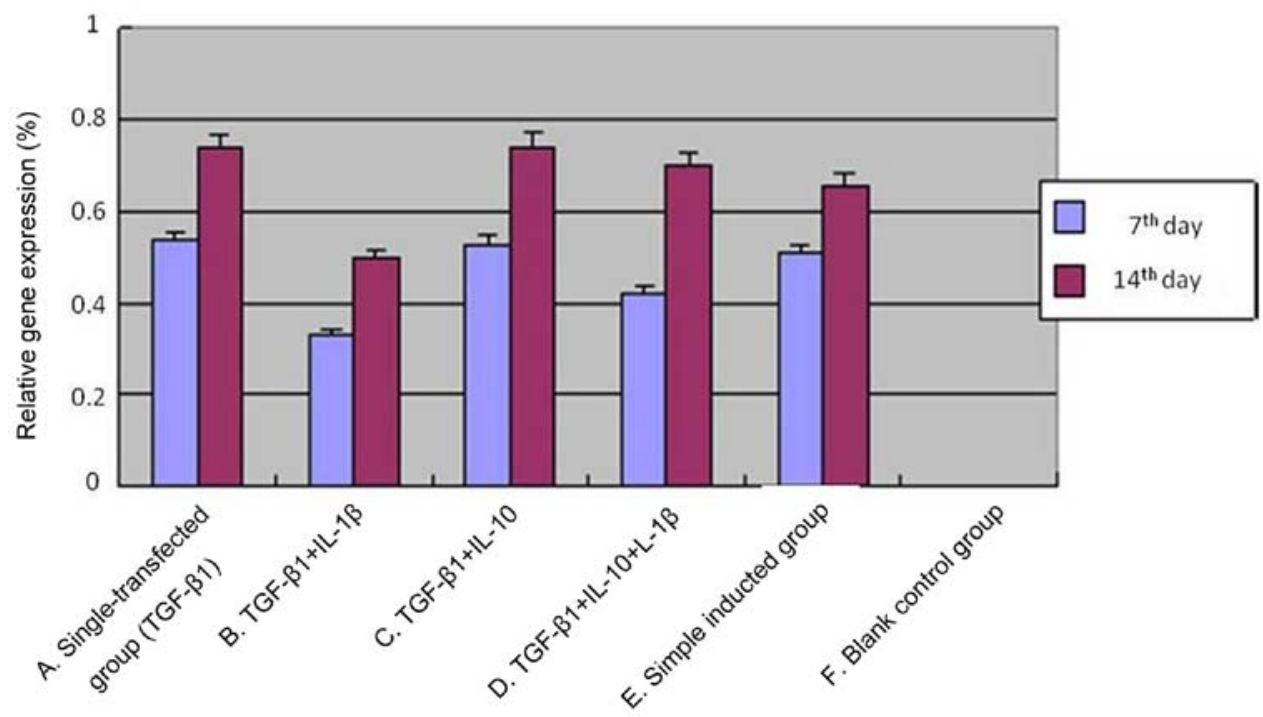

Figure 16. Relative quantification of the gene expression of Type II collagen.

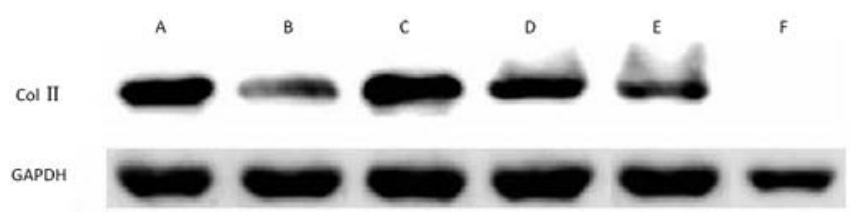

Figure 17. Western blot analysis of Type II collagen (130 kDa) in the different groups. GAPDH was used as a loading control.

chondrocytes. Furthermore, TGF- $\beta 1$ and 3 promote chondrogenesis of MSCs (ref?). IGF-1 can stimulate the anabolic activity of chondrocytes and can induce chondrogenesis of MSC cell types. BMPs, especially BMP-2 and BMP-7, promote chondrogenesis of MSCs and increase matrix production by chondrocytes and MSCs.
Pro-inflammatory cytokines such as IL-1 $\beta$ and tumor necrosis factor (TNF)- $\alpha$ play a crucial role in the pathogenesis of osteoarthritis mediating a cascade of catabolic and pro-inflammatory events (23-25). Chondrocyte apoptosis, a typical feature in osteoarthritic cartilage (26), is accelerated by TNF- $\alpha$ where mitochondria-dependent apoptotic pathways may be activated (27). Elevated concentrations of the immunoregulatory cytokine IL-10 have been demonstrated in osteoarthritic cartilage (28). IL-10 inhibits some catabolic and inflammatory processes in the inflamed joint (29-32). However, its specific role involves the interplay with pro-inflammatory cytokines such as TNF- $\alpha$, whereas its effects on chondrocyte apoptosis in cartilage remains unclear. Regulation of apoptosis by IL-10 has been shown in other cell systems $(33,34)$. IL-10 has recently been found to interfere with TNF- $\alpha$-induced apoptotic pathways in epithelial cells and macrophages $(35,36)$. Wang and 
Lou (37) indicated a direct protective effect of IL-10 from IL-1 $\beta$-induced chondrocyte death. TNF- $\alpha$ elicits a wide range of biological responses including inflammation, cell proliferation, differentiation and apoptosis. Chondrocyte apoptosis is induced by TNF- $\alpha(38-41)$ through its binding to the TNF receptor (TNF-R)1 (p60, $55 \mathrm{kDa})(42)$. Chondrocytes are normally resistant to the induction of apoptosis by IL-1 $\beta$ stimulation (43). It has also been reported that IL-1 $\beta$ protects chondrocytes from CD-95-induced apoptosis by a mechanism that was independent of IL-1 $\beta$-induced NO (43). However, conflicting results have been reported showing IL-1 $\beta$-induced apoptosis in human articular chondrocytes (38). The induction of chondrocyte apoptosis by TNF- $\alpha$ is also arguable because different reports yielded different results. The resistance to cell death of normal chondrocytes exposed to TNF- $\alpha$ or IL- $1 \beta$ is thought to rely on the ability of TNF- $\alpha$ and IL- $1 \beta$ signaling to upregulate protective cellular genes.

In the present study, we have demonstrated that: i) Cultured BMSC grew stably in vitro, proliferated rapidly, had high suitability and could be used as the seed-cells of bone tissue engineering. Bone marrow stromal cells can be induced to differentiate into chondrocytes and osteoblasts under appropriate conditions. ii) Expression of target genes in BMSCs by lentiviral vectors was highly efficient and stable. iii) Cytokines play an important role in cell proliferation and chondrogenic differentiation.

Notably, we observed that cytokines are important in cell proliferation and chondrogenic differentiation. TGF- $\beta 1$ has synergistic effects in the differentiation. In addition, IL-10 may have a protective role in the restoration of cartilaginous tissue. This observation is consistent with several studies on bone marrow cell therapy, which demonstrated important features for tissue healing, although the precise mechanism by which genetically engineered BMSCs confer a therapeutic benefit in the treatment of tissue engineered cartilage remains to be examined.

In conclusion, in the present study, we have identified an optimal Lentiviral-mediated multiple gene transfer system that is safe and capable of transfecting TGF- $\beta 1$ and IL-10, which, when transplanted to meniscal tissue in vitro, continues to express the transgene. These data may be of value for combined cell transplantation and gene therapy approaches using growth factors that promote cartilaginous tissue repair.

\section{Acknowledgements}

The present study was supported by grants from the National Natural Science Foundation of China (no. 81300964), the China Postdoctoral Science Foundation (no. 2013M531611), the China Postdoctoral Science Foundation (no. 2014T70648), the Science and Technology Development Plan Project of Shandong Province (nos. 2014GSF118092 and 2013GSF11850) and the Natural Science Foundation of Shandong Province (nos. ZR2011HM054 and ZR2014HQ041).

\section{References}

1. Centers for Disease Control and Prevention (CDC): Prevalence of doctor - diagnosed arthritis and arthritis - attributable activity limitation - United States, 2007-2009. MMWR Morb Mortal Wkly Rep 59: 1261-1265, 2010.
2. Buckwalter JA and Mankin HJ: Articular cartilage repair and transplantation. Arthritis Rheum 41: 1331-1342, 1998.

3. van den Berg WB, van der Kraan PM, Scharstuhl A and van Beuningen HM: Growth factors and cartilage repair. Clin Orthop Relat Res 391 (Suppl): S244-S250, 2001.

4. Fiorentino DF, Bond MW and Mosmann TR: Two types of mouse T helper cell. IV. Th2 clones secrete a factor that inhibits cytokine production by Th1 clones. J Exp Med 170: 2081-2095, 1989.

5. Moore KW, de Waal Malefyt R, Coffman RL and O'Garra A: Interleukin-10 and the interleukin-10 receptor. Annu Rev Immunol 19: 683-765, 2001.

6. Moroguchi A, Ishimura K, Okano K, Wakabayashi H, Maeba T and Maeta $\mathrm{H}$ : Interleukin-10 suppresses proliferation and remodeling of extracellular matrix of cultured human skin fibroblasts. Eur Surg Res 36: 39-44, 2004.

7. Reitamo S, Remitz A, Tamai K and Uitto J: Interleukin-10 modulates type I collagen and matrix metalloprotease gene expression in cultured human skin fibroblasts. J Clin Invest 94: 2489-2492, 1994.

8. Yamamoto T, Eckes B and Krieg T: Effect of interleukin-10 on the gene expression of type I collagen, fibronectin, and decorin in human skin fibroblasts: Differential regulation by transforming growth factor-beta and monocyte chemoattractant protein-1. Biochem Biophys Res Commun 281: 200-205, 2001.

9. Virk MS, Conduah A, Park SH, Liu N, Sugiyama O, Cuomo A, Kang $\mathrm{C}$ and Lieberman JR: Influence of short-term adenoviral vector and prolonged lentiviral vector mediated bone morphogenetic protein-2 expression on the quality of bone repair in a rat femoral defect model. Bone 42: 921-931, 2008.

10. Naldini L, Blömer U, Gage FH, Trono D and Verma IM: Efficient transfer, integration, and sustained long-term expression of the transgene in adult rat brains injected with a lentiviral vector. Proc Natl Acad Sci USA 93: 11382-11388, 1996.

11. Naldini L, Blömer U, Gallay P, Ory D, Mulligan R, Gage FH, Verma IM and Trono D: In vivo gene delivery and stable transduction of nondividing cells by a lentiviral vector. Science 272: 263-267, 1996.

12. Manilla P, Rebello T, Afable C, Lu X, Slepushkin V, Humeau LM, Schonely K, Ni Y, Binder GK, Levine BL, et al: Regulatory considerations for novel gene therapy products: A review of the process leading to the first clinical lentiviral vector. Hum Gene Ther 16: 17-25, 2005.

13. Sugiyama O, An DS, Kung SP, Feeley BT, Gamradt S, Liu NQ, Chen IS and Lieberman JR: Lentivirus-mediated gene transfer induces long-term transgene expression of BMP-2 in vitro and new bone formation in vivo. Mol Ther 11: 390-398, 2005.

14. Pittenger MF, Mackay AM, Beck SC, Jaiswal RK, Douglas R, Mosca JD, Moorman MA, Simonetti DW, Craig S and Marshak DR: Multilineage potential of adult human mesenchymal stem cells. Science 284: 143-147, 1999.

15. Baltzer AW and Lieberman JR: Regional gene therapy to enhance bone repair. Gene Ther 11: 344-350, 2004.

16. Lieberman JR: Orthopaedic gene therapy. Fracture healing and other nongenetic problems of bone. Clin Orthop Relat Res (Suppl): S156-S158, 2000.

17. Lieberman JR, Ghivizzani SC and Evans $\mathrm{CH}$ : Gene transfer approaches to the healing of bone and cartilage. Mol Ther 6: 141-147, 2002.

18. Gamradt SC and Lieberman JR: Genetic modification of stem cells to enhance bone repair. Ann Biomed Eng 32: 136-147, 2004.

19. Hannallah D, Peterson B, Lieberman JR, Fu FH and Huard J: Gene therapy in orthopaedic surgery. Instr Course Lect 52: 753-768, 2003.

20. Jones AL, Bucholz RW, Bosse MJ, Mirza SK, Lyon TR, Webb LX, Pollak AN, Golden JD and Valentin-Opran A; BMP-2 Evaluation in Surgery for Tibial Trauma-Allgraft (BESTT-ALL) Study Group: Recombinant human BMP-2 and allograft compared with autogenous bone graft for reconstruction of diaphyseal tibial fractures with cortical defects. A randomized, controlled trial. J Bone Joint Surg Am 88: 1431-1441, 2006.

21. Vaccaro AR, Whang PG, Patel T, Phillips FM, Anderson DG, Albert TJ, Hilibrand AS, Brower RS, Kurd MF, Appannagari A, et al: The safety and efficacy of OP-1 (rhBMP-7) as a replacement for iliac crest autograft for posterolateral lumbar arthrodesis: Minimum 4-year follow-up of a pilot study. Spine J 8: 457-465, 2008 . 
22. Swiontkowski MF, Aro HT, Donell S, Esterhai JL, Goulet J, Jones A, Kregor PJ, Nordsletten L, Paiement G and Patel A: Recombinant human bone morphogenetic protein-2 in open tibial fractures. A subgroup analysis of data combined from two prospective randomized studies. J Bone Joint Surg Am 88: 1258-1265, 2006.

23. Blanco Garcia FJ: Catabolic events in osteoarthritic cartilage. Osteoarthritis Cartilage 7: 308-309, 1999.

24. Fernandes JC, Martel-Pelletier J and Pelletier JP: The role of cytokines in osteoarthritis pathophysiology. Biorheology 39: 237-246, 2002.

25. Goldring SR and Goldring MB: The role of cytokines in cartilage matrix degeneration in osteoarthritis. Clin Orthop Relat Res 427 (Suppl): S27-S36, 2004.

26. D'Lima D, Hermida J, Hashimoto S, Colwell C and Lotz M: Caspase inhibitors reduce severity of cartilage lesions in experimental osteoarthritis. Arthritis Rheum 54: 1814-1821, 2006.

27. Blanco FJ, López-Armada MJ and Maneiro E: Mitochondrial dysfunction in osteoarthritis. Mitochondrion 4: 715-728, 2004.

28. Iannone F, De Bari C, Dell'Accio F, Covelli M, Cantatore FP Patella V, Lo Bianco G and Lapadula G: Interleukin-10 and interleukin-10 receptor in human osteoarthritic and healthy chondrocytes. Clin Exp Rheumatol 19: 139-145, 2001.

29. Dayer JM: Cytokines and anti-cytokines in inflammatory rheumatism. Rev Rhum Ed Fr 61: 173S-180S, 1994 (In French).

30. Isomäki P and Punnonen J: Pro- and anti-inflammatory cytokines in rheumatoid arthritis. Ann Med 29: 499-507, 1997.

31. Jorgensen C, Apparailly F, Couret I, Canovas F, Jacquet C and Sany J: Interleukin-4 and interleukin-10 are chondroprotective and decrease mononuclear cell recruitment in human rheumatoid synovium in vivo. Immunology 93: 518-523, 1998.

32. Gonzalez-Rey E, Chorny A, Del Moral RG, Varela N and Delgado M: Therapeutic effect of cortistatin on experimental arthritis by downregulating inflammatory and Th1 responses. Ann Rheum Dis 66: 582-588, 2007.

33. Zhou JH, Broussard SR, Strle K, Freund GG, Johnson RW Dantzer R and Kelley KW: IL-10 inhibits apoptosis of promyeloid cells by activating insulin receptor substrate- 2 and phosphatidylinositol 3'-kinase. J Immunol 167: 4436-4442, 2001.
34. Bouton LA, Ramirez CD, Bailey DP, Yeatman CF, Yue J, Wright HV, Domen J, Rosato RR, Grant S, Fischer-Stenger K, et al: Costimulation with interleukin-4 and interleukin-10 induces mast cell apoptosis and cell-cycle arrest: The role of p53 and the mitochondrion. Exp Hematol 32: 1137-1145, 2004.

35. Rojas M, Olivier M, Gros P, Barrera LF and García LF: TNF-alpha and IL-10 modulate the induction of apoptosis by virulent Mycobacterium tuberculosis in murine macrophages. J Immunol 162: 6122-6131, 1999.

36. Bharhani MS, Borojevic R, Basak S, Ho E, Zhou P and Croitoru K: IL-10 protects mouse intestinal epithelial cells from Fas-induced apoptosis via modulating Fas expression and altering caspase-8 and FLIP expression. Am J Physiol Gastrointest Liver Physiol 291: G820-G829, 2006.

37. Wang Y and Lou S: Direct protective effect of interleukin-10 on articular chondrocytes in vitro. Chin Med J (Engl) 114: 723-725, 2001.

38. Fischer BA, Mundle S and Cole AA: Tumor necrosis factor-alpha induced DNA cleavage in human articular chondrocytes may involve multiple endonucleolytic activities during apoptosis. Microsc Res Tech 50: 236-242, 2000.

39. Aizawa T, Kon T, Einhorn TA and Gerstenfeld LC: Induction of apoptosis in chondrocytes by tumor necrosis factor-alpha. J Orthop Res 19: 785-796, 2001.

40. Aigner T and Kim HA: Apoptosis and cellular vitality: Issues in osteoarthritic cartilage degeneration. Arthritis Rheum 46: 1986-1996, 2002.

41. Schuerwegh AJ, Dombrecht EJ, Stevens WJ, Van Offel JF, Bridts $\mathrm{CH}$ and De Clerck LS: Influence of pro-inflammatory (IL-1 alpha, IL-6, TNF-alpha, IFN-gamma) and anti-inflammatory (IL-4) cytokines on chondrocyte function. Osteoarthritis Cartilage 11: 681-687, 2003.

42. Heyninck K and Beyaert R: Crosstalk between NF-kappaBactivating and apoptosis-inducing proteins of the TNF-receptor complex. Mol Cell Biol Res Commun 4: 259-265, 2001.

43. Kühn K, Hashimoto S and Lotz M: IL-1 beta protects human chondrocytes from CD95-induced apoptosis. J Immunol 164: 2233-2239, 2000. 